UNIVERSITY of NORTH FLORIDA.

\section{Journal of Counseling Sexology \& Sexual} Wellness: Research, Practice, and Education

\title{
Sexual Wellness and Rare Disease Considerations: A Behavioral Case Conceptualization and Approach to Counseling Treatment
}

\author{
Jessica Z. Taylor \\ Central Methodist University \\ Chrystal L. Lewis \\ University of South Alabama \\ Leslie E. Davis \\ University of Missouri-St. Louis
}

Follow this and additional works at: https://digitalcommons.unf.edu/jcssw

Part of the Counseling Commons

\section{Recommended Citation}

Taylor, J. Z., Lewis, C. L., \& Davis, L. E. (2019). Sexual Wellness and Rare Disease Considerations: A Behavioral Case Conceptualization and Approach to Counseling Treatment. Journal of Counseling Sexology \& Sexual Wellness: Research, Practice, and Education, 1 (2). https://doi.org/10.34296/01021018

This Article is brought to you for free and open access by the Brooks College of Health at UNF Digital Commons. It has been accepted for inclusion in Journal of Counseling Sexology \& Sexual Wellness: Research, Practice, and Education by an authorized administrator of UNF Digital Commons. For more information, please contact Digital Projects.

(C) 2019 All Rights Reserved

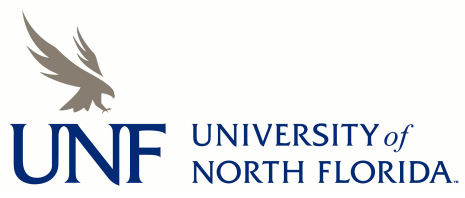




\title{
Sexual Wellness and Rare Disease Considerations: A Behavioral Case Conceptualization and Approach to Counseling Treatment
}

\author{
Jessica Z. Taylor \\ Central Methodist University
}

\author{
Chrystal L. Lewis \\ University of South Alabama
}

\author{
Leslie E. Davis \\ University of Missouri-St. Louis
}

\begin{abstract}
Sexual wellness is infrequently addressed with individuals with a rare disease. Counselors must be competent in working with sexual wellness issues, especially those related to medical conditions, since clients may not share those concerns with healthcare providers. This article presents a case scenario involving a client living with a rare disease called Hereditary Angioedema, the symptoms of which present challenges to her intimate and sexual relationship with her partner due to unpredictable and painful swelling. A behavioral theoretical lens is used to conceptualize the case scenario and inform treatment. Implications for counselor competency, interdisciplinary collaboration, and client empowerment toward advocacy are discussed.
\end{abstract}

Keywords: rare disease, swelling, sensate focus, systematic desensitization, counselor competency

\section{Introduction}

Approximately one in ten people in the United States has a rare disease, with over 7,000 uniquely identified rare diseases (Genes, 2019). Healthcare providers often lack knowledge of rare diseases, thereby increasing an individual's frustration with healthcare experiences. With increasing frustration in general, individuals may not disclose to their healthcare providers secondary issues stemming from their rare disease, such as their sexual wellness. Even in cases where individuals do disclose secondary issues, those pertaining to their sexuality are not frequently discussed (Anllo, 2016; Catamero et al., 2017) or inquired about by healthcare providers (Jensen, Broesby-Olsen, Bindslev-Jensen, \& Nielsen, 2018). Krebs (2007) comprehensively documents how patients do not voluntarily discuss sexual concerns with their healthcare providers.

When individuals feel that secondary issues stemming from their rare disease are not being heard or taken seriously by their healthcare providers, counselors and other mental health professionals may instead become tasked with addressing such secondary issues in counseling. Even when healthcare providers do approach the individual's rare disease seriously, many physicians report needing additional assistance from non-physicians (e.g., counselors) to fully manage all aspects of the disease (SHIRE, 2013). Kravitz et al. (2006) found some support for physicians making mental health referrals, but physicians' offices were not found to be likely to offer significant assistance in helping individuals follow-through on mental health referrals. Hammer,
Spiker, and Perrin (2018) discussed how most patients will initially seek mental health assistance through their primary care provider, but only about one third will follow through on a referral to a mental health provider.

Clients experiencing concerns related to sexual wellness as a secondary issue of their rare disease may initially present in counseling with a relationship issue. Krebs (2007) discussed ways that relational factors may influence sexual functioning in individuals diagnosed with a medical illness. Identifying and addressing the secondary issue in counseling may be crucial for the client to resolve the initial presenting concern and have a positive perception of the counseling treatment.

Notably, the therapeutic alliance and relationship factors are strongly associated with therapeutic treatment outcomes (Horvath, Re, Flückiger, \& Symonds, 2011; Suzuki \& Farber, 2016). When a client initially seeks assistance for an issue, it may take time to develop a trusting therapeutic relationship. Once the client senses that the counselor is an em-

\begin{tabular}{|c|}
\hline Corresponding Author \\
\hline Jessica Z. Taylor \\
Central Methodist University \\
2458 Old Dorsett Road, Suite 200 \\
Maryland Heights, MO 63043 \\
E: jztaylor@ centralmethodist.edu \\
P: (314)227-4410 \\
\hline
\end{tabular}


pathic person, this client perception plays a part in shaping the strength of the therapeutic relationship (Horvath, 2015). Once the client has this trusting perception of the counselor, then a client may be more likely to share sexual issues in sessions. Understandably, the more clients perceive counselors as being empathic and open to discussing sexual stressors, the more likely they become to disclose ways in which their presenting concerns are influenced by any sexual concerns.

Even when clients perceive that counselors might be receptive to discussing relevant sexual issues, counselors and other types of mental health providers often do not directly ask clients about their sexual concerns (Hipp \& Carlson, 2019; Miller \& Byers, 2009). Levine, Risen, and Althof (2016) identified numerous primary concerns counselors may have in addressing client sexual issues: (a) being unaccustomed to talking about sex, (b) not knowing what sexual information is necessary to ask about, (c) not understanding something the client shares, (d) being uncertain how to respond to clients disclosing sexual concerns, and (e) embarrassing the client. These concerns may lead the counselor to avoid discussing topics related to client sexuality. Unfortunately, clients often do not discuss sexual issues unless the counselor asks in a way that demonstrates openness and comfort in discussing the topic (Miller \& Byers, 2011).

In addition to potentially lacking knowledge about addressing sexual issues in counseling, counselors may also lack knowledge about rare diseases since that is not a counselor's specialty area. Even healthcare professionals with a medical background may lack knowledge regarding rare diseases. For example, Shire (2013) found that $67 \%$ of patients with rare diseases frequently had to provide education on their rare disease to their healthcare provider. There is no one specialty which oversees all rare diseases. Each rare disease presents unique concerns and challenges for which there may not be extensive research to inform treatment. As an example, 93-95\% of rare diseases have no FDA approved treatment (Orphanet, 2018). With over 7,000 identified rare diseases, it would be outside the typical scope of competence for counselors to have more knowledge on rare diseases than healthcare professionals.

In addition, training in topics related to sexuality and sexual wellness are not competency areas covered by the Council for Accreditation of Counseling and Related Education Programs' (CACREP; 2016) core curricular standards. Unless a counselor attended a CACREP-accredited marriage, couple, and family counseling program, in which Standard 5.F.2.e - human sexuality and its effect on couple and family functioning - is required within the specialty area's contextual dimension curricular standards, it is possible for counselors to have no formal education in addressing client sexuality or sexual wellness issues. Furthermore, even if counselors have had formal training as a part of their educational background, they may still experience discomfort or hesi- tancy in discussing sexual issues with individual clients or couples (Hipp \& Carlson, 2019; Levine et al., 2016).

A case scenario for a client with a type of rare disease called Hereditary Angioedema (HAE) is presented below to illustrate how secondary issues pertaining to sexuality and sexual wellness may initially present to counseling as a relationship issue involving concerns with one's partner. HAE incidence estimates range between 1 in 30,000 and 1 in 50,000 (Maurer et al., 2018). HAE's common symptoms include facial, tongue, airway, abdominal, extremities, and genital swelling (Maurer et al., 2018). These swells can be extremely painful, with abdominal swells frequently causing extreme diarrhea and vomiting. A swell that begins in one location can also travel to another location. Thus, a swell that begins in the hands could travel to the abdominal area and then subsequently to the face and airway. The pathophysiology of how or why the swells travel remains unknown. These swells can be spontaneous without a precipitating factor, or they can be triggered by seemingly innocuous activities with repetitive motion such as painting, hammering, or mowing the lawn. Thus, seemingly innocuous sexual encounters can lead to genital swelling in patients with HAE.

The client in the below case scenario represents an amalgamation of multiple individual experiences vocalized through HAE-specific support groups, rather than the experience of any singular individual with HAE. A theme discussed in these support groups, but not known to be present in the literature, is the overall impact of HAE on sexual experiences and the subsequent impact on the quality of life for these individuals and their partners. Although sexual activity is known to be a possible trigger for a severe swell (Banerji \& Riedl, 2016), no known literature addresses counseling interventions for individuals with HAE experiencing fear surrounding sexual activities with a partner due to the possibility of a swell. This paper applies empirically-supported behavioral counseling approaches to the case scenario below to address the client's experienced fear.

\section{Case Scenario}

A 33-year-old heterosexual female client, "Jane," initially presents to individual counseling with concerns about her relationship with her significant other "Paul." Jane states that she and Paul have grown apart, do not speak as often as they used to, and she is afraid that he will leave her. Upon further exploration, Jane reveals she frequently experiences fatigue related to a rare disease called Hereditary Angioedema (HAE). Jane explains that HAE causes her to have intermittent, unpredictable severe swelling that requires quick medical intervention to prevent swelling from closing her airways. Jane has most commonly experienced swelling in facial mucosal tissues (e.g., mouth, tongue, and lips), but she has also experienced swelling in her hands, stomach, legs, and genitals. Jane confirms that she is under a physician's 
care for HAE, but she has not disclosed the locations of all her swelling, such as the genital swelling, to her healthcare team.

Upon hearing that the swelling has the potential to affect her genital region, the counselor asks Jane about how HAE has affected her sexual relationship with herself and with Paul. Initially appearing surprised that the counselor asked about her sexuality, Jane cautiously states that overall, HAE has not affected her desire for sexual activities with herself or Paul. She reports engaging in self-stimulation when desired without any complications. Jane emphasizes that her primary sexual concern relates to increasingly denying Paul's sexual advances.

The counselor asks Jane to share more about what leads her to deny Paul's sexual advances since she states having sexual desire for intimacy with Paul and is concerned about him leaving her. Jane shares that in addition to the fatigue she experiences from HAE, she also experiences apprehension and anxiety due to some past sexual encounters. The counselor remains open to learning more and asks Jane what has happened in the past that contributes to her present apprehension toward sexual activity with Paul.

Jane shares that three months ago, after providing oral sex to Paul, she suffered from mouth and lip swelling. Paul then commenced intercourse as they had done in the past, not realizing the client's mouth and lips were swelling. Jane did not mention it at the time because she felt guilty asking Paul to stop because she wanted him to be satisfied. Jane admits that she also wanted to be satisfied through intercourse, which was another reason she did not ask him to stop. Jane states her swelling can be inconsistent in severity, and she had hoped the swelling would not become worse. Jane shares that additional swelling developed in her genital area during intercourse, and after intercourse basic functions such as sitting in a chair or even elimination were painful because of the swelling brought on by intercourse. Jane thinks that she may not have been as lubricated during intercourse as she has been at other times without swelling problems, and the resulting abrasive friction may have contributed to the genital swelling. Jane did not tell Paul about the pain she experienced afterward because she did not want him to feel to blame for her being in pain. She also did not tell her healthcare providers about what happened because she is not comfortable talking to them about how sex has occasionally caused swells. Additionally, her healthcare providers have never asked her about how her sexuality has been affected by HAE symptoms, so she is uncertain how they would respond if she were to mention it.

Jane reports often feeling shame and guilt for increasingly denying Paul's advances for sexual intimacy due to fatigue and fear of sexual activities resulting in swelling even though swelling has not been a consistent problem for her every time she engages in sexual activity. Jane is concerned that if she is unable to get past her fear of engaging in sexual or intimate activities with Paul that he will end their relationship or engage in an affair to meet his basic sexual or intimacy needs. Jane claims that she has always considered herself to be a sexual person, desiring to pleasure and be pleasured within a relationship. She feels she is having trouble comfortably reengaging with Paul in a sexual way after the painful incident involving genital swelling. She sees this as what is underlying her current relationship issues with Paul. Jane asks her counselor how counseling might be able to help her get past her feelings of fear and guilt related to engaging in sexual activity with Paul.

\section{Special Considerations}

First and foremost, a counselor working with a client affected by a rare disease would want to develop therapeutic rapport and trust to strengthen the therapeutic relationship (Horvath, 2015). Throughout Jane's case, the counselor remains open and nonjudgmental while learning about Jane's experiences within her relationship with Paul. While developing trust and rapport with Jane, the counselor would also want to validate and normalize Jane's experiences by sharing how living with medical illness is known to have the potential to affect one's relationship and sexual functioning (Krebs, 2007).

Once Jane perceives the counselor as empathic and willing to collaborate with her to address her concerns, the counselor would want to obtain a release of information to speak directly with the client's healthcare team to coordinate care. The counselor would want to learn more about the specific medical condition and any activities that would be medically ill-advised, both from the client's healthcare team as well as from organizations specializing in rare diseases, such as the National Organization for Rare Disorders (NORD) and Global Genes. In situations like Jane's, where the client may be uncomfortable mentioning sexual activities to healthcare providers, counselors may assist in advocating for the importance of sexual wellness by directly asking about it when speaking with the healthcare team. Directly inquiring about any ill-advised sexual behaviors not only normalizes sexuality as a basic human need for many individuals (Maslow, 1943), but it also might encourage the healthcare team to follow up with clients like Jane about any experienced problems with sexual activity. Considering sexual activity may be perceived as a basic physiologic function for many individuals, as long as the healthcare team does not identify all sexual activities as medically ill-advised, counselors can deem relevant perceived client needs related to sexuality just as important as any other identified biopsychosocial need (Engel, 1977).

Specific to the rare disease HAE in Jane's case scenario, medical treatments continue to become available that can help manage symptoms of the disease. However, new medi- 
cal innovations to manage disease symptoms do not eradicate fear experienced due to events prior to the release of newer medications. When working with clients affected by HAE and other rare diseases, counselors should explore what medications clients were taking when they experienced adverse events related to their presenting concerns. Newer medications that can manage symptoms more effectively may not have been available or affordable when the client experienced past significant physical symptoms. Counselors should ensure they discuss medication history with a client's healthcare team as a part of care coordination.

For Jane's case scenario, some points are especially important to emphasize. Swelling influenced by HAE is not a consistent medical issue. Although swelling may have occurred previously from a specific trigger, this does not guarantee swelling will occur again at the same severity the next time the trigger is experienced. Swelling is more likely to occur when individuals have been experiencing heightened levels of stress or recent swelling in other body locations (Zuraw, 2008). Discussions within HAE support communities related to swelling from sexual activity have identified contact with abrasive surfaces (e.g., fingernails, callouses, or uneven edges on toys) as especially likely to lead to problematic swelling. Issues from abrasive surfaces tend to be more problematic in sexual activities with another individual if the individual is unaware of the abrasive surface or why it may be problematic.

Minimal discussion within HAE support communities mentions self-stimulation. Since individuals tend to have enough self-awareness to stop self-stimulation if they start to feel initial signs of a swell, this may help explain why self-stimulation is relatively unheard of as a common trigger for HAE swelling. Alternatively, individuals with HAE who are aware of the swelling risks posed by abrasive surfaces may take more precautions in avoiding any abrasive surfaces when engaging in self-stimulation. Notably, stimulation of mucosal tissue itself does not guarantee swelling. Swelling tends to be due to more complex factors that can make a swell's severity difficult to predict.

Finally, the treatment strategies identified in the treatment plan below are merely suggestions that may be discussed collaboratively with clients. All identified treatment strategies are supported in clinical practice for a variety of presenting client concerns. Currently, there is no known literature addressing how to work with clients experiencing fear of engaging in sexual activities due to previous adverse reactions from a rare disease. When many healthcare providers offer minimal information to help address sexual wellness needs of individuals with rare diseases, counselors can collaboratively offer suggestions from clinical practice to the client that are not contraindicated by the client's healthcare team.

\section{Case Scenario Conceptualization}

Prior to developing a treatment plan for Jane, her counselor would want to develop a case conceptualization that is theoretically grounded. When counselors theoretically conceptualize client situations, they gain a clearer tentative idea about what has contributed to the client's presenting situation through their chosen theoretical lens. From this theoretically-informed understanding of the client, the counselor can then select possible treatment approaches aligned with the chosen theoretical lens. When the conceptualization process is overlooked in favor of going directly to treatment planning, "there may be treatment chaos" (Berman, 2015, p. 1) due to limited intentional client understanding guided by theory. Jane's case will be explored through a behavioral therapeutic lens prior to discussing possible treatment approaches.

The case scenario demonstrates that if the counselor had not further inquired about Jane denying Paul's sexual advances, the counselor would have missed important information. The couple's intimate relationship and Jane's concerns about her partner's satisfaction within the relationship are influenced by prior experiences of unpredictable adverse physical effects during sexual activity as influenced by her rare disease. The counselor would have also missed how prior adverse physical sensations after sexual activity continue to affect Jane's engagement in intimate and sexual activities with her partner.

In behaviorism, the primary focus of counseling is on behaviors (Berman, 2015). Even more specifically, a counselor approaching this case scenario from a behavioral lens would want to conduct a functional analysis of the antecedents (i.e., what occurs before the indicated behavior) and the consequences (i.e., what occurs after the indicated behavior) to better understand what has led to the development of the indicated behavior and what serves to continue the indicated behavior. In this case scenario, Jane appears to be presenting primarily with concerns about reduced behavioral engagement in sexual activity with Paul.

In exploring what has led to Jane denying Paul's advances, the counselor begins to see how the behavior of denying advances has become classically conditioned, partly due to physical symptoms resulting from her rare disease. Jane's initial physical reason for denying Paul's sexual advances fatigue - is a common reason stated by individuals for denying sexual advances, which may have no etiology from a rare disease or any other sort of medical condition but rather general life stressors (Basson, 2001). Jane's perceived fatigue may serve as an unconditioned stimulus, leading to the unconditioned response of denying sexual advances. However, as the counselor learns by further inquiring about Jane's feelings of denying advances, her existing fatigue, her prior physical experiences of swelling mucosal tissues, and subsequent fear of the outcome from engaging in sexual activities 
are potential activators of the sympathetic nervous system. A fear response as described above can activate the sympathetic nervous system, resulting in a potential reduction in natural lubrication and unintentional vaginal muscle constriction (Fleischman, Hamilton, Fessler, \& Meston, 2015), and may serve as conditioned stimuli leading to the now conditioned response of denying sexual advances. Furthermore, this conditioned fear of outcomes from sexual activity may have generalized to other intimate behaviors involving mucosal tissues, such as kissing, which may result in Jane being apprehensive of any physical intimate behavior with Paul. This generalization of fear related to intimate behaviors can help explain her concerns about Paul not having his basic intimacy needs met and what choices he might make in meeting those needs.

In exploring what has led to Jane's continuation of denying Paul's advances, the counselor begins to see how that behavior has become operantly conditioned, partly due to physical symptoms resulting from her rare disease. Jane stated that during a previous sexual experience with Paul in which her genitalia swelled (unrelated to any other physical cause - such as vaginismus - but rather as a symptom of the rare disease), she did not mention it to Paul due to already feeling shame and guilt from past instances of denial. Jane experienced significant pain afterward in basic functions involving the general genital area. This pain experienced afterward has positively punished her engagement in sexual activities, meaning her engagement in sexual activities has declined as a result of the introduction of aversive physical sensations from sexual activity. Additionally, this reduction in engagement in sexual activity leading to painful outcomes has negatively reinforced her feelings of guilt and shame surrounding not only sexual activity, but also her relationship with Paul in general. Jane continues to experience ongoing feelings of shame and guilt after the reduction of sexual activities, which she now perceives as aversive due to unpredictable painful sensations. Despite Jane's ongoing feelings of shame, Jane, similar to many other individuals with rare diseases, experiences a hope for change, particularly after starting new orphan drug therapies (Wastfelt, Fadeel, \& Henter, 2006).

\section{Case Scenario Goals and Treatment Planning}

Jane initially presented to counseling with concerns about her relationship with her partner. These concerns continue to be evident after a more thorough exploration of the experiences and reasons behind Jane's presenting concern related to her rare disease. Notably, the direction for treatment can be driven by Jane's fears regarding adverse physical outcomes from engaging in intimate and sexual activity with Paul - and her resulting feelings of shame and guilt - while remaining consistent with a behavioral theoretical conceptualization of the client's situation. Jane's chosen long-term goal can be understood as increasing intimate behaviors with her partner. This long-term goal may be broken down into two separate short-term goals: a) deconditioning fear related to intimate behaviors with Paul and b) increasing effective communication behaviors with Paul.

\section{Short-Term Goal and Treatment Planning: Decondition- ing Fear of Intimate Behavior}

Systematic desensitization. Systematic desensitization involves the notion that one cannot be tense and relaxed simultaneously (Wolpe, 1968). In using systematic desensitization, Jane can work on extinguishing the conditioning of fear with intimate behaviors and instead pair feelings of relaxation with her thoughts toward intimate behaviors with Paul. In doing so, a counselor would first have Jane identify a fear hierarchy, in which she allocates a level of fear toward different types of intimate behaviors. She may start with the thought of kissing Paul on the cheek - potentially a lowerlevel fear that could still lead to unpredictable swelling of her mouth's mucosal tissues - and work her way up to the thought of penetrative intercourse with Paul, which could lead to unpredictable swelling in her genital region and resulting pain. Once a fear hierarchy has been developed, the counselor would help Jane learn relaxation exercises, such as progressive muscle relaxation, deep breathing, or mindfulness. After Jane practices relaxation techniques, the counselor would then start the systematic desensitization process. In this process, the counselor would ask Jane to imagine various items on her fear hierarchy, starting from the lower-level fears and gradually working up to the higherlevel fears. Jane would perform her relaxation techniques simultaneously while imaging her fearful events. As such, she would work toward classically conditioning feelings of calmness with fearful thoughts about intimate behaviors, so as to reduce the experienced fear presently paired with them. Gradually, from working through her fear hierarchy in this manner, Jane could learn to extinguish perceived feelings of fear with thoughts of engaging in intimate behaviors with Paul.

Sensate focus. Sensate focus can also be used as an alternative to systematic desensitization that involves moving through a hierarchy of intimate behaviors with a partner, so as to reduce fear associated with engaging in intimate and sexual behaviors (Linschoten, Weiner, \& Avery-Clark, 2016; Weiner, Cannon, \& Avery-Clark, 2014). Sensate focus involves five stages which focus on intimate touching for one's own understanding of how temperature, pressure, and texture affect the individual's physical sensations (Weiner et al., 2014). Clients and their partners start by taking turns exploring each other's bodies through touch, while avoiding intimate areas such as breasts and genitals. As couples continue to move through the stages of sensate focus, they gradually involve more intimate areas, mutual touching, mutual touching with genitals making external contact, and moving to- 
ward genitals making internal contact. Even if arousal occurs, the practicing partners are encouraged to be mindful of it, but not focus on it or demand that arousal lead to orgasmic completion. The focus is not on one's own pleasure or partner's pleasure - but rather, the focus is on understanding and building awareness of how one's body responds to intimate physical sensations.

For Jane, learning about sensate focus in individual counseling and then introducing the process to Paul at home could help her unpair her current feelings of fear with engaging in intimate behaviors by increasing her understanding of what physical sensations and intimate behaviors her body responds to safely without leading to signs of impending swelling. During the earlier stages of sensate focus in which intimate areas are avoided, she could include any areas involving mucosal tissue since those have presented risks for unpredictable swelling in the past. For more detailed information on the stages of sensate focus, refer to Weiner et al. (2014). No known research exists examining the use of sensate focus for intimacy concerns in clients with HAE; however, sensate focus may be a helpful tool for clients seeking to address their sexual wellbeing with a partner as a relevant basic physiologic need (Maslow, 1943). Before suggesting sensate focus to clients with HAE or other rare diseases, counselors would want to have cleared such behaviors with the client's healthcare team.

\section{Short-Term Goal and Treatment Planning: Increasing Effective Communication Behavior with Partner}

The second short-term goal involves Jane increasing effective communication behaviors with Paul. This second shortterm goal is influenced by the conceptual understanding of (a) Jane's denial of activities after experiencing significant pain during sexual activity and (b) Jane's continuation of feelings of shame and guilt after denying activities as having been operantly conditioned through positive punishment and negative reinforcement, respectively. Therapeutic approaches for increasing effective communication behaviors with Paul may involve assertiveness training or couples counseling to increase Jane's advocacy of her own needs and limits related to intimate behaviors. These strategies may also encourage Paul to express his thoughts on having his needs met, as well as provide a space for Jane to engage in conversation about her feelings of guilt and shame.

Assertiveness training. Wolpe (1968) identified assertiveness training as one approach to reciprocal inhibition - the process of experiencing relaxation while simultaneously imagining or experiencing an anxiety-inducing situation. Some individuals may experience anxiety related to discussing their needs and limits related to intimate behaviors with others. However, the importance of communicating intimate and sexual needs has been found to be crucial for emotional well-being, especially that of women (Ferroni \& Taffe,
1997). For individuals experiencing fear of verbally asserting their needs and limits, sensate focus may provide a nonverbal way to assert one's physical preferences and improve overall communication within relationships (Linschoten et al., 2016). The use of handriding - placing one's hand over a partner's hand during sensate focus to non-verbally communicate positive or negative sensations - may positively reinforce and communicate behaviors leading to comfortable sensations while negatively punishing and communicating behaviors leading to uncomfortable sensations (Weiner et al., 2014). If Jane were to perceive initial signs of potential swelling, she could guide Paul's hand away from that area to communicate a limit against continuing to touch that part of her body at that time. If Paul were to avoid areas that had previously led to swelling, but Jane was not getting initial signs of potential swelling during a particular instance of sensate focus, she could guide Paul's hand to that part of her body to communicate approval of him touching her there at that time. In this way, sensate focus can also help alleviate anxiety for partners of individuals with medical conditions with inconsistent symptomology who may be afraid of hurting their partner during intimate activities (Linschoten et al., 2016).

Couples counseling. Counselors can also invite partners to participate in couples counseling to provide an open and safe space to communicate a variety of needs within the couple's relationship. D'Ardenne (2004) wrote about ways in which couples need to develop coping strategies when one partner within a relationship has been diagnosed with a longterm illness, due to having to modify activities of daily living depending on the nature of the illness. Similarly, couples experiencing medical illness within their relationship may find themselves needing to renegotiate ways of being sexually intimate and satisfying each other's sexual needs, within the confines of any physical limitations or concerns related to the illness (Gilbert, Ussher, \& Perz, 2008).

In the case scenario, Paul could be encouraged in couples counseling to express his current thoughts regarding the present lack of intimate behavior and discuss potential coping strategies to allow for him to meet his needs while also respecting Jane's physical comfort level. Additionally, Jane could openly communicate about her current feelings of guilt and shame about the decrease in their intimate activities, her denial of Paul's advances, as well as her fear of Paul leaving the relationship to meet his sexual needs in other ways (Esmail, Munro, \& Gibson, 2007). Due to Jane having a rare and long-term illness, her physical sensations of unpredictable and life-threatening swelling are unlikely to simply go away or have simple solutions. The couples counselor can invite Jane and Paul to openly express their feelings and their thoughts on how they can safely modify and re-evaluate intimacy for Jane's safety (Appleton, Robertson, Mitchell, \& Lesley, 2018). The couples counselor could also encourage 
Jane to speak with her healthcare providers about how her physical illness is affecting her psychosocial wellbeing and relationship with Paul, which are important elements of palliative medical care (Cort, Monroe, \& Oliviere, 2004).

\section{Implications for Counseling Practice}

One of the first overall implications for counseling practice involves counselors increasing their competency on issues pertaining to sexual wellness in counseling, as well as their comfort in discussing these sorts of issues in counseling. Hipp and Carlson (2019) speak to this important need in their recent article in The Family Journal. Without competency in discussing sexual issues with clients, counselors may lead treatment from their own potential countertransference or personal value system, instead of working collaboratively with clients toward validating their experience of sexual and intimacy difficulties while living with a serious medical illness and offering appropriate treatment approaches. Without comfort in discussing sexual issues with clients, counselors may ignore their clients' sexual concerns entirely, leaving them to continue feeling alone and their social wellbeing ignored by treatment professionals (Mercadante, Vitrano, \& Catania, 2010).

The recent creation of the Association of Counseling Sexology \& Sexual Wellness (ACSSW) through the American Counseling Association speaks to the importance of sexuality in counseling being understood and discussed more openly as a counseling competency. The ACSSW's (2019) Research and Scholarship committee is currently working on developing a list of counselor competencies "in the area of human sexuality that professional counselors should be expected to demonstrate as part of their independent practice" (Research and scholarship section, para. 2). These upcoming professional resources aim to enhance counselors' knowledge base and skillset in working with client sexuality issues in counseling.

A second implication for counseling practice involves counselors engaging in interdisciplinary collaboration with healthcare professionals when working with clients experiencing concerns influenced by medical conditions. This becomes especially important when a client has a rare disease. Ideally, counselors would want to obtain a release from the client to speak with the client's healthcare team. If the client does not currently have a healthcare team or does not trust their healthcare team's knowledge of their illness, a medical consultation with an expert on that condition could assist the counselor in better understanding how the disease may impact the client's psychosocial wellbeing and relationships. When counselors understand the client's medical situation, they can help the client learn to modify activities of living and live life with the disease, rather than just focus solely on the disease itself (Jensen et al., 2018).

Similarly, a third implication for counseling practice in- volves counselors advocating for clients' holistic wellbeing when clients have a medical illness or rare disease. Palliative care is a medical care model with a focus on symptom management and maximizing holistic quality of life (National Coalition for Hospice and Palliative Care, 2018). Unfortunately, due to a general lack of knowledge and confusion with hospice care, palliative care is infrequently offered to individuals with long-term rare diseases (Adams, Miller, \& Grady, 2016). If counselors enhance their knowledge about palliative care and holistic wellbeing for individuals experiencing medical conditions, they could provide psychoeducation about palliative care and encourage clients to broach the topic with their healthcare providers. This may be especially crucial if clients do not perceive their healthcare provider as viewing their sexual wellness as an important medical concern, in comparison to treating the rare disease (Mercadante et al., 2010). Additionally, counselors could provide psychoeducation on the importance for clients to advocate for their emotional, social, and spiritual needs with their healthcare providers, in addition to their physical needs (National Coalition for Hospice and Palliative Care, 2018). In the case scenario above, the counselor could suggest Jane practice advocating for these various needs to her healthcare team as a part of assertiveness training. Although counselors cannot provide medical treatment and are not medical experts, they can empower clients with information so they can advocate for their own medical and palliative care needs with their healthcare providers.

\section{Conclusion}

Among the many secondary concerns that may accompany a rare disease, concerns related to sexual wellness may be among those less frequently addressed by healthcare providers. When this is the case, counselors may find themselves seeing these clients, even though clients may not present with an initial concern clearly relating to their sexual wellness. This article discussed a case scenario involving a client living with a rare disease called HAE, the symptoms of which present challenges to her intimate and sexual relationship with her partner due to unpredictable and painful swelling. By viewing the case scenario through a behavioral theoretical lens, and allowing that theoretical lens to inform treatment, a counselor could work with this hypothetical client to address her feelings of fear of engaging in physical intimacy with her partner, as well as her feelings of shame and guilt related to denying sexual advances from her partner. When counselors can become competent in working with sexual wellness issues and comfortable exploring these concerns with clients, clients may perceive their concerns being heard and addressed by a professional for the first time since receiving their medical diagnosis. By counselors approaching client sexuality concerns with competency and willingness to discuss them, counselors may be able to empower 
clients to bring up these valid concerns with their healthcare providers in order to explore their treatment options. In doing so, counselors may help enhance an element of quality of life for individuals with rare diseases and serious medical conditions.

\section{References}

Adams, L. S., Miller, J. L., \& Grady, P. A. (2016). The spectrum of caregiving in palliative care for serious, advanced, rare diseases: Key issues and research directions. Journal of Palliative Medicine, 19(7), 698705. doi:10.1089/jpm.2015.0464

Anllo, L. M. (2016). Challenges of sexual life after breast and prostate cancer. In S. B. Levine, C. B. Risen, \& S. E. Althof (Eds.), Handbook of clinical sexuality for mental health professionals (p. 235-249). Routledge.

Appleton, D., Robertson, N., Mitchell, L., \& Lesley, R. (2018). Our disease: a qualitative metasynthesis of the experiences of spousal/partner caregivers of people with multiple sclerosis. Scandinavian Journal of Caring Sciences, 32(4), 1262-1278. doi:10.1111/scs.12601

Association of Counseling Sexuality \& Sexual Wellness. (2019). Acssw committees. Retrieved from https:// WWW . counselingsexology . com/committees

Banerji, A., \& Riedl, M. (2016). Managing the female patient with hereditary angioedema. Women's Health, 12(3), 351-361. doi:10.2217/whe.16.6

Basson, R. (2001). Human sex-response cycles. Journal of Sex E Marital Therapy, 27(1), 33-43. doi:10.1080/00926230152035831

Berman, P. S. (2015). Case conceptualization and treatment planning: Integrating theory with clinical practice (3rd ed.). Sage.

Catamero, D., Noonan, K., Richards, T., Faiman, B., Manchulenko, C., Devine, H., ... Board (2017). Distress, fatigue, and sexuality: Understanding and treating concerns and symptoms in patients with multiple myeloma. Clinical Journal of Oncology Nursing, 21(5), 7-18. doi:10.1188/17.cjon.s5.7-18

Cort, E., Monroe, B., \& Oliviere, D. (2004). Couples in palliative care. Sexual and Relationship Therapy, 19(3), 337-354. doi:10.1080/14681990410001715454

Council for Accreditation of Counseling and Related Educational Programs. (2016). 2016 standards for accreditation. Council for Accreditation of Counseling and Related Educational Programs. Retrieved from http:// www . cacrep . org/wp-content/uploads/2017/ 08/2016-Standards-with-citations.pdf

D'Ardenne, P. (2004). The couple sharing long-term illness. Sexual and Relationship Therapy, 19(3), 291308. doi:10.1080/14681990410001715427
Engel, G. (1977). The need for a new medical model: a challenge for biomedicine. Science, 196(4286), 129-136. doi: $10.1126 /$ science. 847460

Esmail, S., Munro, B., \& Gibson, N. (2007). Couple's experience with multiple sclerosis in the context of their sexual relationship. Sexuality and Disability, 25(4), 163-177. doi:10.1007/s11195-007-9054-8

Ferroni, P., \& Taffe, J. (1997). Women's emotional well-being: The importance of communicating sexual needs. Sexual and Marital Therapy, 12(2), 127-138. doi:10.1080/02674659708408155

Fleischman, D. S., Hamilton, L. D., Fessler, D. M. T., \& Meston, C. M. (2015). Disgust versus lust: Exploring the interactions of disgust and fear with sexual arousal in women. PLOS ONE, 10(6), e0118151. doi:10.1371/journal.pone.0118151

Genes, G. (2019). Rare facts. Retrieved from https:// globalgenes.org/rare-facts/

Gilbert, E., Ussher, J. M., \& Perz, J. (2008). Renegotiating sexuality and intimacy in the context of cancer: The experiences of carers. Archives of Sexual Behavior, 39(4), 998-1009. doi:10.1007/s10508-008-9416-Z

Hammer, J. H., Spiker, D. A., \& Perrin, P. B. (2018). Physician referral to a psychologist: Testing alternative behavioral healthcare seeking models. Journal of Clinical Psychology. doi:10.1002/jclp.22729

Hipp, C. J., \& Carlson, R. G. (2019). Comfort in treating sexual problems: Current training and counselor self-efficacy. The Family Journal, 27(2), 105-114. doi: $10.1177 / 1066480719835342$

Horvath, A. O. (2015). Therapeutic/working alliance. The Encyclopedia of Clinical Psychology, 1-5. doi:10.1002/9781118625392.wbecp262

Horvath, A. O., Re, A. C. D., Flückiger, C., \& Symonds, D. (2011). Alliance in individual psychotherapy. Psychotherapy, 48(1), 9-16. doi:10.1037/a0022186

Jensen, B., Broesby-Olsen, S., Bindslev-Jensen, C., \& Nielsen, D. S. (2018). Everyday life and mastocytosis from a patient perspective-a qualitative study. Journal of Clinical Nursing, 28(7-8), 1114-1124. doi:10.1111/jocn.14676

Kravitz, R. L., Franks, P., Feldman, M., Meredith, L. S., Hinton, L., Franz, C., ... Epstein, R. M. (2006). What drives referral from primary care physicians to mental health specialists? a randomized trial using actors portraying depressive symptoms. Journal of General Internal Medicine, 21(6), 584-589. doi:10.1111/j.15251497.2006.00411.x

Krebs, L. U. (2007). Sexual assessment: Research and clinical. Nursing Clinics of North America, 42(4), 515529. doi:10.1016/j.cnur.2007.07.004

Levine, S. B., Risen, C. B., \& Althof, S. E. (2016). Handbook of clinical sexuality for mental health profession- 
als. Routledge.

Linschoten, M., Weiner, L., \& Avery-Clark, C. (2016). Sensate focus: a critical literature review. Sexual and Relationship Therapy, 31(2), 230-247. doi:10.1080/14681994.2015.1127909

Maslow, A. H. (1943). A theory of human motivation. Psychological Review, 50(4), 370-396. doi:10.1037/h0054346

Maurer, M., Magerl, M., Ansotegui, I., Aygören-Pürsün, E., Betschel, S., Bork, K., ... Craig, T. (2018). The international WAO/EAACI guideline for the management of hereditary angioedema-the 2017 revision and update. Allergy, 73(8), 1575-1596. doi:10.1111/all.13384

Mercadante, S., Vitrano, V., \& Catania, V. (2010). Sexual issues in early and late stage cancer: a review. Supportive Care in Cancer, 18(6), 659-665. doi:10.1007/s00520-010-0814-0

Miller, S. A., \& Byers, E. S. (2009). Psychologists' continuing education and training in sexuality. Journal of Sex $\mathcal{F}$ Marital Therapy, 35(3), 206-219. doi:10.1080/00926230802716336

Miller, S. A., \& Byers, E. S. (2011). Practicing psychologists' sexual intervention self-efficacy and willingness to treat sexual issues. Archives of Sexual Behavior, 41(4), 1041-1050. doi:10.1007/s10508-011-9877-3

National Coalition for Hospice and Palliative Care. (2018). Clinical practice guidelines for quality palliative care. Author. Retrieved from https: / /wWw . nationalcoalitionhpc . org/ wp-content/uploads/2018/10/NCHPC -NCPGuidelines_4thED_web_FINAL.pdf

Orphanet. (2018). Orphan drugs in the united states of america. Retrieved from http://www. orpha.net/ consor/cgi-bin/Education_AboutOrphanDrugs .php?lng=EN\&stapage=ST_EDUCATION _EDUCATION_ABOUTORPHANDRUGS_USA

SHIRE. (2013). Rare disease impact report: Insights from patients and the medical community. Retrieved from https://globalgenes.org/wp-content/ uploads/2013/04/ShireReport-1.pdf

Suzuki, J. Y., \& Farber, B. A. (2016). Toward greater specificity of the concept of positive regard. PersonCentered $\mathcal{E}$ Experiential Psychotherapies, 15(4), 263284. doi:10.1080/14779757.2016.1204941

Wastfelt, M., Fadeel, B., \& Henter, J. (2006). A journey of hope: lessons learned from studies on rare diseases and orphan drugs. Journal of Internal Medicine, 260(1), 1-10. doi:10.1111/j.1365-2796.2006.01666.x

Weiner, L., Cannon, N., \& Avery-Clark, C. (2014, September/October). Reclaiming the lost art of sensate focus: A clinician's guide. Family Therapy Magazine. Retrieved from http://wWW.sextherapiststlouis
. com/files/SensateFocus0nly . pdf

Wolpe, J. (1968). Psychotherapy by reciprocal inhibition. Conditional Reflex: A Pavlovian Journal of Research $\mathcal{E}$ Therapy, 3, 234-240.

Zuraw, B. L. (2008). Hereditary angioedema. New England Journal of Medicine, 359(10), 1027-1036. doi:10.1056/nejmcp0803977 